Article

\title{
The Triple Bottom Line on Sustainable Product Innovation Performance in SMEs: A Mixed Methods Approach
}

\author{
Lucía Muñoz-Pascual ${ }^{1, *(\mathbb{D})}$, Carla Curado ${ }^{2}$ (D) and Jesús Galende ${ }^{1(\mathbb{C}}$ \\ 1 Multidisciplinary Institute for Enterprise (IME), Department of Business Administration and Management, \\ University of Salamanca, Campus "Miguel de Unamuno", Building FES, 37007 Salamanca, Spain; \\ jgalende@usal.es \\ 2 Advance/CSG ISEG, University of Lisbon, Rua do Quelhas, 6, 1200-781 Lisbon, Portugal; \\ ccurado@iseg.ulisboa.pt \\ * Correspondence: luciamp@usal.es; Tel.: +34-923294500 (ext. 6825)
}

Received: 24 January 2019; Accepted: 18 March 2019; Published: 20 March 2019

\begin{abstract}
Small- and medium-sized enterprises (SMEs) contribute enormously to a country's sustainable growth. Developing the pathways that lead to sustainable innovation in SMEs represents an important aspect of the business world and society. The aim of this article is to verify the relations and pathways that lead to sustainable product innovation performance while considering all three pillars of the Triple Bottom Line Approach. This study used a mixed methods approach to identify the antecedents of sustainable product innovation performance. Our approach applied structural equation modeling and fuzzy-set qualitative comparative analysis. The structural equation model was used to measure the effects of the three pillars of the triple bottom line: economic, social, and environmental developments. The structural equation model was also designed to account for the firm's type (Public Limited Companies vs. General Partnerships). Using the structural equation model, we determined whether a firm's type moderates the effects of the three pillars. Furthermore, using fuzzy-set qualitative comparative analysis, we identified alternative configurations of conditions and determined those that are likely to lead to sustainable product innovation performance and those that result in its absence. The sample comprises data from 349 Portuguese small and medium enterprises. The findings show that social and environmental developments are two important antecedents for product innovation performance, and they contribute to different pathways that lead to product innovation performance. In addition, in General Partnerships, human resource costs are important for sustainable product innovation performance. Therefore, the results of both the quantitative and qualitative analyses underline the relevance of the triple bottom line approach to product innovation performance.
\end{abstract}

Keywords: sustainable product innovation performance; adoption of environmental practices; net exports; human resource costs; organizational learning capability; knowledge sharing

\section{Introduction}

The aim of this study is to answer three research questions: How are economic, social, and environmental aspects balanced in innovation activities? What is needed to make the triple bottom line approach more effective (e.g., new communications, new human resources practices, and knowledge sharing management methods)? Does a firm's legal form (e.g., public limited companies versus general partnerships) affect its commitment toward sustainable innovation?

These research questions are very interesting to the business world because their answers can facilitate an understanding of the key processes and pathways that allow companies to manage and 
integrate the three development goals with the most common innovation dynamics, e.g., knowledge search strategies and human resource management. Such a shift often calls for organizational restructuring and more diverse knowledge components or new routines, thus leading to novel pathways toward innovation. Furthermore, sustainable development requires a "society pool" approach to innovation whereby different stakeholders (e.g., trade partners, employees, governments for innovation's projects) are involved. In addition, our research questions examine differences in innovation performance between SMEs with different legal forms. SMEs with different legal forms can have different sustainability goals.

In this study, we used a mixed methods approach to identify the antecedents of the adoption of environmental practices (PRAC) and sustainable product innovation performance (PIP) in the context of the triple bottom line approach (TBL). The adoption of environmental practices by a firm requires it to respond satisfactorily to the concerns of its various stakeholders (such as employees, customers, and suppliers) and address issues specific to its location [1]. However, there are few studies that have analyzed innovation and sustainable development together from a TBL perspective [2,3]. Most firms' innovation efforts focus on only one development goal at a time, whereas the approach used here accounts for the economic, social, and environmental developments that lead to sustainable innovation, which benefits society. This study adopted a TBL to address a major gap in the literature on small- and medium-sized enterprises (SMEs) by using a novel mixed methods approach (quantitative and qualitative). While previous research has focused primarily on the PRAC of large companies, interest in the sustainability of SMEs has grown for at least two reasons. SMEs are the backbone of the economy and represent more than $95 \%$ of enterprises across the world [4]. The PRAC of SMEs is significantly different from that of large companies as a result of several peculiarities: owners directly manage most SMEs; they are tightly linked to business partners and the local community; and they have financial, human, and time resource limitations that can hinder the implementation of PRAC commensurate to larger firms [5]. For these reasons, this study used a sample of Portuguese SMEs. This study also addressed sustainable paths for two SME types: Public Limited Companies (PLC) and General Partnerships (GP).

The literature recognizes that innovative activity, especially that of SMEs, is beneficial to society: increased employment, economic prosperity, and more competitive economies are among the advantages [6]. A company demonstrates innovative behavior by its desire to earn profits and acquire power and prestige, even at the expense of society. However, PIP often produces socially beneficial outcomes, and we propose herein that PRAC is positively related to PIP. Thus, we endeavored to expand our understanding of the specific antecedents that lead to sustainable PIP.

This study applied the TBL to the sustainable PIP of SMEs. Specifically, we examined how the following aspects lead to PRAC and sustainable PIP: the effects of the degree of internationalization (measured by net exports), the costs of human resources (as a \% of firm invoices), organizational learning capability at the firm level, and knowledge sharing at the interorganizational level.

This study makes several contributions. First, we extend the sparse literature on antecedents of sustainable PIP in SMEs by empirically analyzing the extent to which economic and social factors drive engagement in sustainability through the TBL. Second, our model identified SME types that can enhance the effects of the antecedents. Third, we used information from the managers of Portuguese SMEs to test the model with a mixed methods approach. Initially, we applied structural equation modeling (SEM) to test our hypotheses. Then, we applied fuzzy-set qualitative comparative analysis (fsQCA) to identify alternative pathways within the proposed model that lead to sustainable PIP. Therefore, this study used a double methodology to explain the effects of TBL on PIP.

The study aims to contribute to the fields of sustainability, technology, and human resource management (HRM) within SMEs by using a mixed methods approach (SEM and fsQCA). The remainder of this paper proceeds as follows: Section 2 provides a comprehensive description of the constructs and the formulation of the hypotheses. In Section 3, we introduce the methods, the 
sample, and the measurement assessment. Section 4 reports the survey's results. Section 5 contains a discussion and conclusions.

\section{Literature Review and Hypotheses}

\subsection{Triple Bottom Line Approach}

Since the 2005 world summit on social development, societies have been expected to design their growth strategies according to the three main sustainable development goals, i.e., economic development, social inclusion, and environmental protection, which reflect the three pillars of the triple bottom line approach characterizing sustainable business development [7,8]. In recent years, one of the key topics tackled by the sustainable development discourse concerns the interrelated relationship between firms' innovation dynamics and sustainability. Indeed, the development and diffusion of sustainable innovations by companies have been deemed necessary conditions for the successful application of the triple bottom line approach, thus favoring social and environmental responsiveness while boosting economic growth [9]. Accordingly, sustainable innovations represent a means through which organizations can actually foster sustainable development [10]. At the same time, current sustainability challenges can become a source of inspiration for novel innovative trajectories, which may enhance firms' competitiveness and contribute to the construction of a better society [11]. However, academics have noticed that more than 20 years after sustainable development was first conceptualized, the triple bottom line approach is far from being the dominant business model for companies [12,13]. Furthermore, most firms' innovation efforts focus on only one development goal at a time, and research has yet to provide an in-depth discussion on how to reconcile the three sustainability pillars in innovation dynamics [2,3].

The previous arguments emphasize that more research is needed to fully comprehend the interrelated nature of firms' innovation dynamics and sustainability. Furthermore, sustainable development requires a 'society pool' approach to innovation whereby different stakeholders (e.g., employees, customers, suppliers, and governments) are involved [14-16]. On the one hand, stakeholders' involvement helps to clarify the criteria for sustainable outcomes and then operationalize new strategic practices for innovation according to these criteria. In addition, there remains considerable uncertainty as to whether sustainable innovations actually lead to a more sustainable society [12].

Therefore, we propose the following research questions:

How are economic, social, and environmental aspects balanced in innovation activities?

What is needed to make the triple bottom line approach more effective (e.g., new communications, new human resources practices, and knowledge sharing management methods)?

$\bigcirc$ Does a firm's legal form (e.g., public limited companies versus general partnerships) affect its commitment toward sustainable innovation?

\subsection{Economic Development}

Economic development ought to be a dimension that deals with the bottom line and the flow of money. It may involve looking at income or expenditures, business climate factors, employment, and business diversity factors. Specific examples include Personal income, Human Resource Cost, Establishment churn, Job growth, Percentage of firms in each sector, internationalization, and so forth. In this paper, we propose two important dimensions of economic development. First, one external dimension of a firm: Internationalization. Second, one internal dimension of a firm: Human Resource Cost.

\subsubsection{Internationalization}

Internationalization is the process through which a firm expands its sales of goods or services around the world [17]. Internationalization is a strategy that is intended to increase a firm's 
competitive advantage and thus its value through enhanced economies of scale, growth opportunities, and diversification benefits while gaining access to new resources and knowledge [18]. Therefore, some authors have considered international experience to be a relevant knowledge-based resource that can improve firms' PRAC [19]. International firms are exposed to new and different ideas from diverse national contexts and various social, cultural, and environmental challenges. Thus, they can leverage the diverse knowledge acquired [20]. Companies that operate in foreign markets also gain experience in communicating, negotiating, and building relationships with stakeholders. This experience is conducive to developing a greater sensitivity to successful approaches to adapting their PRAC to the local context [21]. Different empirical studies have shown the positive effect of internationalization on firms' environmental and social activities. Recently, Attig [18] provided evidence of the link between internationalization and PRAC by using a large sample of firms from 44 countries. Therefore, foreign operations should lead to greater engagement in PRAC and sustainable PIP.

In addition, exports can lead to the development of PIP for several reasons. First, international competition stimulates efforts to reduce costs, increase quality, and become more flexible, all of which force the company to continuously invest in technology and update and adapt their products. Further, with exports, the company increases the size of its market and thus increases its return and economies of scale. This is especially important given the significant fixed costs involved in PIP [22]. Thus:

Hypothesis 1. Net exports have a positive effect on practice (PRAC).

\subsubsection{Human Resource Cost}

Investments in human resources should be oriented toward improving a firm's performance by instilling a culture of values in its employees [23].

Human resources include three dimensions (intellectual, emotional, and social) that interact with each other to generate synergies that improve organizational capabilities [24]. The continuous improvement of employees through new investments can lead to new PRAC and ideas for sustainable PIP [25]. Within each dimension of human resources, companies can invest in the development of a type of resource (knowledge, motivation, relationships) [24]. These resources are the source of new PRAC and sustainable PIP because they are unique and valuable [26]. Consequently:

Hypothesis 2. Human resource costs have a positive effect on practice (PRAC).

\subsection{Social Development}

Social development refers to the social dimensions of a firm, community, or region and can include measurements of education, equity, and access to social resources, health and well-being, quality of life, and social capital. The examples listed below are a small snippet of potential variables: Female labor force participation rate, Median income, Relative poverty, Percentage of employees with a post-secondary degree or certificate, Organizational learning capability, Interorganizational knowledge sharing, and so forth. In this paper, we propose two important dimensions of social development. First, one internal dimension of firms: Organizational Learning Capability. Organizational Learning Capability is a relevant tool for SMEs because it grants access to social resources. In this way, SMEs with a high level of Organizational Learning Capability can collect and report information about what is going on inside and outside the company. Second, one external dimension of firms: Interorganizational Knowledge Sharing. Knowledge Sharing is another key tool to improve the social capital that is exchanged between companies. For instance, knowledge sharing may help to improve business partner relations, co-create new ideas and projects, share new viewpoints, and, consequently, have a greater knowledge of the social and business reality. 


\subsubsection{Organizational Learning Capability}

Organizational learning capability (OLC) refers to the importance that facilitators place on organizational learning [27]. Organizational learning represents the refinement and renewal of dynamic knowledge. The renewal of knowledge assets provides the ability to learn and explore new knowledge while exploiting existing knowledge [28]. Organizational learning occurs in a context that consists of "both the organization and its external environment" [29].

Lichtenthaler [30] classified organizational learning into three processes: explorative, exploitative, and transformative. All three processes have positive effects on PRAC and sustainable PIP. Organizational learning requires organizations to plan, envision, and transact. According to Chiva et al. [31], OLC comes from experimentation, risk-taking, interaction with the external environment, dialogue, and participative decision-making.

Experimentation is the extent to which firms try out new ideas, are curious about how things work, or carry out changes in work processes. Risk-taking reflects the tolerance of ambiguity, uncertainty, and errors that facilitate organizational learning. Interaction with the external environment is the extent of the relationships that a firm has with its immediate environment. Dialogue is defined as a sustained collective inquiry into the processes, assumptions, and certainties that compose everyday experience.

Finally, participative decision-making refers to the level of influence that employees have in the process. A degree of ambiguity and inconsistency still surrounds the question of how OLC affects PRAC and sustainable PIP [32]. Accordingly:

Hypothesis 3. Organizational learning capability has a positive effect on practice (PRAC).

\subsubsection{Knowledge Sharing}

Knowledge sharing (KS) refers to a firm's ability to exploit information from business partners or to identify market opportunities [33]. Interorganizational KS enables firms to achieve a competitive advantage in rapidly changing business environments [34]. Interorganizational KS is a complex issue with strategic importance for PRAC and sustainable PIP [35]. Firms determine the level of KS by the perceived benefits, such as information exchange, social satisfaction, and dependence among the partners [36]. The ability to share knowledge influences an SME's sustainable innovation.

The current knowledge on whether and how firms can leverage relational capital and KS for sustainable innovation is equivocal. The existing research has conceptualized few of the underlying processes responsible for mobilizing relational capital; thus, it has yielded mostly contradictory empirical results. We consider KS to be a resource of intellectual capital exchange between firms [37]. Following Kianto et al. [38], knowledge is the most important resource for PIP in firms. Xie et al. [39] reported the positive effect of interorganizational links on PIP. Participation in interfirm KS appears to be an effective approach to obtaining new mechanisms and information to develop PRAC and sustainable PIP [34]. In this paper, we analyze how KS at the interorganizational level contributes to the development of PRAC and sustainable PIP in SMEs. Since knowledge is the core factor that supports effective and efficient decision-making, KS contributes to the creation of a competitive advantage. Therefore:

Hypothesis 4. Knowledge sharing has a positive effect on practice (PRAC).

\subsection{Environment Development}

Environmental dimensions should represent the adoption of natural resources and reflect potential influences on its viability. It could incorporate air and water quality, energy consumption, natural resources, solid and toxic waste, and land use/land cover. Ideally, organizations should track long-range trends for each of the environmental dimensions to help identify the impacts that a 
project, policy, or product will have on an area, market, or community. In this context, we focus on a complete concept: Adoption of Environmental Practices in SMEs.

\section{Adoption of Environmental Practices}

The reinforcement of environmental regulations worldwide in recent years has motivated firms to pursue environmental management practices [40]. Similarly, researchers have found that the main economic or social factors leading to the adoption of environmental practices are exports (internationalization), new investments in human resources, organizational learning capability, and knowledge sharing. In the case of SMEs, the main stakeholders in PRAC are customers, the government, local society, employees, and suppliers; other stakeholders include competitors, insurers, banks, and firms in the area [41].

In addition, PRAC may directly affect sustainable PIP since it might require the application of more efficient methods of consumption and waste recycling, and a consequence of such methods is a reduction in the total amount of the company's operational costs [42]. Aragón-Correa et al. [43] showed that a proactive environmental strategy requires changes in routines and operational methods. Chan and Hawkins [44] added that the adoption of environmental practices helps to achieve better safety standards and healthier working conditions. Moreover, companies that are proactive in environmental practices can take advantage of public support or governmental subsidies [45].

Fresner and Engelhardt [46] asserted that the adoption of environmental practices is very beneficial to SMEs and produces an immediate and visible improvement in organizational efficiency and PIP. Considering the above-offered arguments, we propose $\mathrm{H} 1, \mathrm{H} 2, \mathrm{H} 3$, and $\mathrm{H} 4$.

\subsection{Product Innovation Performance for Sustainable Development}

PIP is the result of successfully exploiting new knowledge and sustainability [47]. This process comprises technical design, research and development, manufacturing, management, and the commercial activities that constitute the marketing of a new (or improved) product. Innovation involves two dimensions: technical and nontechnical; however, studies have mainly addressed the former [48]. On the basis of the relevant literature, we analyzed both dimensions while considering certain configurations of nontechnical innovations (OLC, KS, and PRAC) that stimulate the development of sustainable PIP [49].

Product innovation performance involves two dimensions: efficiency (PIP_EFFICI) and efficacy (PIP_EFFICA) [50]. Innovation efficiency reflects the effort spent to achieve a certain degree of success, while innovation efficacy reflects an innovation's degree of success. The innovation process includes several stages from discovery to implementation [51] that make success dependent on a firm's efforts. This process plays an important role in the success of innovation [52].

SMEs can achieve sustainable development through innovation if they take care of the process of innovation development. Thus, our study offers a complete analysis of PIP on the basis of different indicators ranging from the preparation to the implementation of the activities necessary for the development of PIP. Authors such as Curado et al. [53] have indicated that PIP_EFFICI has a positive effect on PIP_EFFICA. Therefore, if we introduce PRAC as a set of activities that help in the preparation, implementation, and start-up of innovation, we can achieve PIP and, as a result, sustainable development. Consequently:

Hypothesis 5. Practice (PRAC) has a positive effect on product innovation performance (PIP) for Sustainable Development.

\subsection{Firm Type}

The firm's organizational structure and its type can affect the adoption of environmental practices and sustainable PIP. Therefore, the adoption depends on whether a firm is a PLC or GP. 


\subsubsection{Public Limited Companies}

A PLC is an organization type that is widely used among medium and large companies in which all capital is divided into shares. One of the characteristics of a PLC is that the responsibility of each partner is proportional to their share of the capital. Therefore, participating in a PLC has a fairly high level of financial security. In addition, a PLC is a personal organic structure. This means that you can act as a legal person. The founding of a PLC requires very high initial capital: in Portugal, the minimum capital is $€ 50,000$. In practically all legislation around the world, a PLC requires two or three obligatory events: The general shareholders' meeting (or assembly) is the venue in which all shareholders meet. One of its charges is the election of the company's administrators. The administrators are the managers that make up the executive team and, at the same time, are the representative body. The supervisory board has the task of supervising the administrators.

\subsubsection{General Partnerships}

In contrast to a PLC, a GP contracts debts. The partner or partners will only respond to them in relation to the amount of money contributed to the firm. The GP is an organization type widely used by SMEs. GPs have rules for the transmission of capital contributions, accounting, and internal bodies, and these rules differentiate them from PLCs. In Portugal, the minimum capital for a GP is $€ 5000$. The required bodies of the general meeting make important decisions and are responsible for the election of the administrators. In addition, last year's accounts are approved during the general meeting. The administrators are in charge of the management of the firm. There can be one, two, or more administrators.

The size, the organizational structure, and the legal form of the company are important aspects that can influence behavior, strategy, adoption of environmental practices, and, consequently, innovation. For instance, depending on its legal form, a company may have access to different amounts of funding under different conditions for the development of new innovation projects. In addition, the legal form of the company may influence the adoption of environmental practices. In light of these differences, we argue that the firm type moderates the main effects of the TBL on sustainable PIP. Therefore:

Hypothesis 6. The firm's type has a moderating effect on hypotheses H1-H5.

\subsection{Alternative Configurations}

The configuration theory asserts that more than one configuration of conditions may lead to the same result [54] — equifinality. The conditions that lead to the outcome differ from those that lead to its absence. A configuration is a specific combination of conditions that produces an outcome of interest. Configurations of conditions enable us to model complexity, even for a limited number of conditions.

Configurational approaches admit that conditions can be causally related in one configuration, yet they can be unrelated or even inversely related in others. Such configurations expose asymmetric characteristics and synergetic effects that replace the traditional bivariate interaction effects. The consideration of complexity and ambiguity leads to nonlinear relations. Following the best practices for using fsQCA [54], we should explore the sets of alternative configurations that lead to both the outcome and its absence. Applied to this study, we propose the following:

Hypothesis 7. Alternative configurations exist that lead to PIP.

Hypothesis 8. Alternative configurations exist that lead to the absence of PIP.

The proposed model is summarized in Figure 1: 


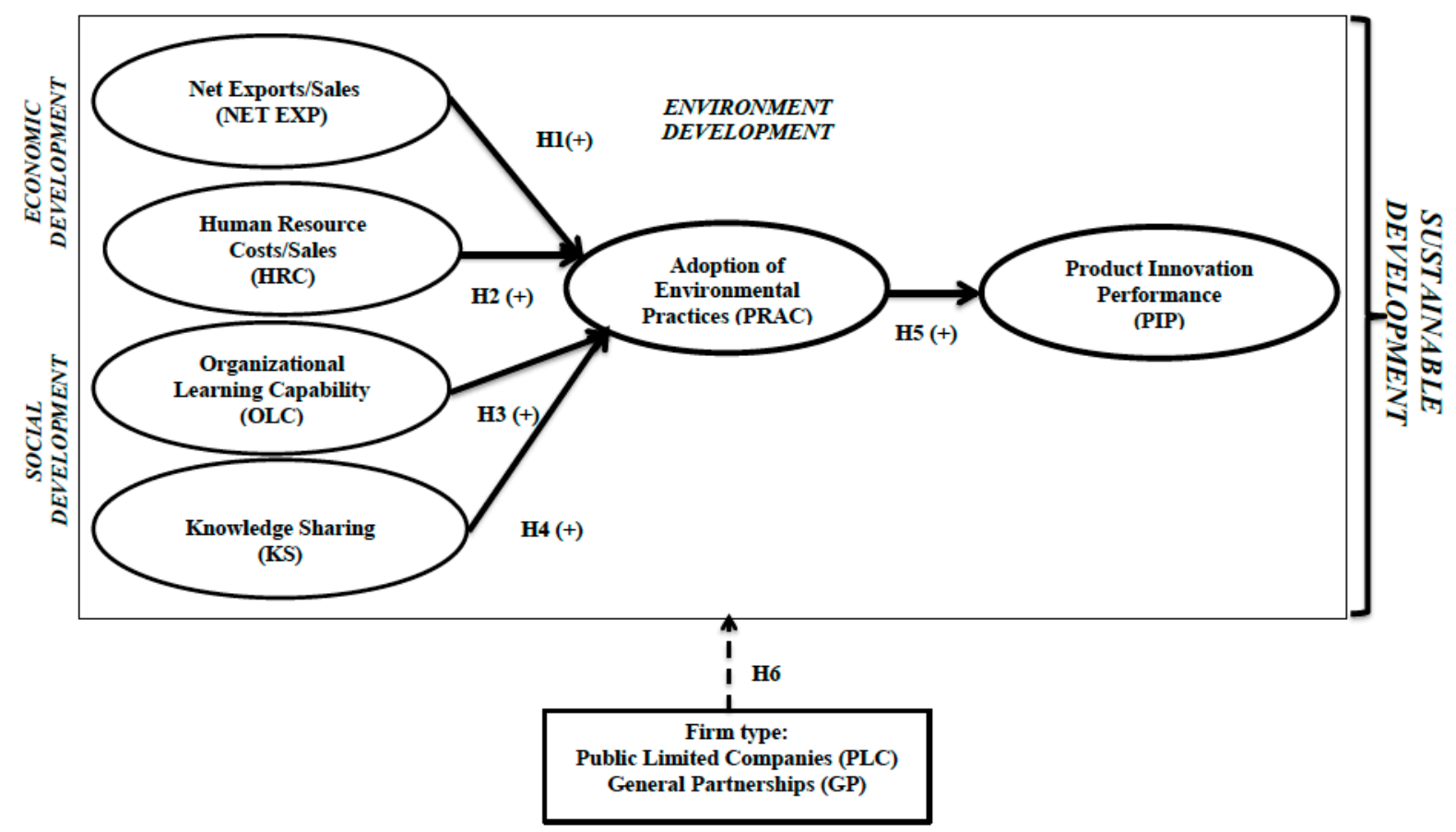

H7: There are alternative configurations leading to PIP.

H8: There are alternative configurations leading to the absence of PIP

Note: This paper uses the SEM for H1-H6 and the fsQCA for H7-H8 (configurations for PIP and PIP)

Figure 1. Research model for Sustainable PIP: the triple bottom line approach.

\section{Methods}

Following Bhatti et al. [34], we applied a quantitative method to test for sustainable PIP (Hypotheses H1-H6). However, are quantitative methods sufficient to explain PIP? Further, Osabutey and Jin [55] argued that traditional quantitative methods have important limitations in their ability to account for complex interactions between variables. Other recent studies have applied qualitative methods. Ozkan-Canbolat and Beraha [56] used fsQCA, which identifies the necessary and core conditions of the configurations that lead to the outcome variable or its absence (Hypotheses $\mathrm{H7}$ and H8). The main empirical contribution of this paper is the combination of quantitative and qualitative methods to explain sustainable PIP in firms [57]. Few mixed method studies have offered both a quantitative and qualitative comparative analysis of PIP $[32,53,57]$. Therefore, this paper presents a complete study on the antecedents and paths to sustainable PIP.

\subsection{Mixed Methods Approach}

Research as a way of knowing, interpreting, and transforming reality cannot ignore the constant demands of an increasingly unstable, complex, and diverse business world; hence, for some researchers $[32,53,58]$, the two traditional research approaches (qualitative and quantitative) fall short in the resolution of problems and situations that require new perspectives. In this context, the application of mixed methods approaches is important, and it allows us to exploit the strengths of both approaches to achieve more complete understandings of economic, social, and environmental problems [59].

This paper contributes to the study of sustainable development and PIP with a mixed methods approach. First, and from a quantitative perspective, we applied SEM. SEM is a complex statistical technique for studying causal relationships between variables with direct and indirect effects. In addition, we used a multigroup analysis for testing one moderating variable in the model. Secondly, and from a qualitative perspective, we applied fsQCA, which is a relevant statistical technique for 
studying alternative configurations that lead to PIP. Our study therefore provides a unique, complete, and coherent understanding of sustainable development and PIP.

The mixed methods approach can be defined as a kind of research that combines quantitative and qualitative techniques, methods, approximations, concepts, and language in a holistic study [60].

Our paper's objective is the study of PRAC and PIP through the analysis of data using two different statistical techniques at the same time; this methodology leads to a complete and joint interpretation of the results. In accordance with Creswell and Plano [60], this is a triangulation design for the application of the mixed methods approach. In short, the mixed methods approach

(1) Combines the strengths provided by the two approaches.

(2) Attenuates the weaknesses of their separate application.

(3) Allows for a better understanding of PRAC and PIP.

This means that quantitative and qualitative methods are not incompatible. Moreover, their combination is relevant when looking for the causes and conditions that lead companies to sustainable PIP [61].

\subsection{Sample}

The data were collected using an online survey that was sent to 6846 Portuguese certified innovative SMEs in several industry categories: manufacturing, power, and gas supply; water supply and pollution; building; vehicle trade and repair; transport and storage; catering; information and communication; housing; scientific activities; administrative activities; health activities; and other services. The survey garnered 385 responses. After applying adequate cleaning procedures [62], the final sample comprised 349 firms (5.1\% response rate).

The surveys were managed online using the Qualtrics Survey Software. To minimize the probability of errors due to the interpretation of the language used, the survey was initially drafted in English, and the back-translation method was used for the survey items. Therefore, the questionnaire was originally written in English, translated into Portuguese by a certified translator, and then back-translated into English. Before the survey's design, a pre-test was carried out with five prestigious scholars and managers who helped to draft the final survey. Finally, the firms were contacted by telephone to introduce the study, and mass mailings of the survey were then sent to them. The survey took 20 minutes, and the respondents were the CEOs within each firm.

CEOs are responsible for making decisions, and they know all of the information and tools required for economic, social, and environmental development and PIP. In this sense, CEOs have a realistic and broad vision, and they know the firm's situation for the development of PIP.

Most of the respondents were female (56.4\%), held graduate or post-graduate degrees $(76.5 \%)$, were an average of 43.6 years old, and had tenure of more than five years $(77.4 \%)$ at their firm. With respect to the firms, $92.4 \%$ were 10 years old or more, and the majority $(65.9 \%)$ had 50 employees or fewer; $63.6 \%$ were PLCs, and $36.4 \%$ were GPs. To check for possible nonresponse bias, we used a time-trend extrapolation test to compare late and early respondents. The late respondents are those whose responses we received after the first round of mailing, that is, after the follow-up. These respondents are very similar to non-respondents given that they would have fallen into that category without the follow-up efforts [63]. A one-way analysis of variance (ANOVA) showed no significant difference between the early and late responses in terms of measures such as the firm's size (numbers of employees) and age. Thus, the sample was representative of the population.

\subsection{Variables}

The research model is composed of three dimensions for sustainable PIP.

The first dimension is economic development. This dimension is composed of two relative variables: Net exports (NET_EXP) and Human resource costs (HRC). Both variables are measured using information obtained directly from the firms in the sample. NET_EXP measures the volume 
of net exports, that is, the difference between exports and imports [18]. HRC measures the total expense that the firm incurs from the processes and practices of human resources as determined by its proportion of the firm's total invoicing [23].

To measure the constructs, we adopted a Likert-type scale that ranges from 1 (strongly disagree) to 7 (strongly agree) [64].

The second dimension is social development. This dimension is composed of two variables: OLC and KS. OLC uses a five-dimensional scale [65]: experimentation (E_OLC), risk-taking (R_OLC), interaction with the external environment (I_OLC); dialogue (D_OLC), and participative decision-making (P_OLC). The KS scale comes from Chen et al. [66]. With this measure, we aimed to quantify the social development that the company can generate internally and externally. For this, we first established whether the company has OLC at the organizational level. A company that manages to develop this capacity can more easily generate social development inside and outside of the organization. For example, it can attract new talents and absorb new routines. Secondly, at an intergovernmental level, that is, between companies and institutions, we assessed whether the company is capable of generating and sharing knowledge. This is a sign that the company knows how to listen, understand, and apply, together with its partners, the new knowledge and information demanded by our society.

The third dimension for sustainable development is environmental development. This dimension is composed of one variable: PRAC. PRAC is measured by using the five-item scale from Molina-Azorín et al. [67].

Finally, the sustainable PIP's two-dimensional scale (PIP_EFFICI and PIP_EFFICA) comes from Alegre et al. [50].

We also performed a confirmatory factor analysis (CFA) by using AMOS ${ }^{\circledR}$ (SPSS Inc., Chicago, IL, USA) to assess the validity of the measurements. We only retained the 35 items that met the recommended levels [62] indicative of good measurement validity.

The uni-dimensionality among the items in each variable was confirmed. An item-to-total correlation was used to determine convergent validity, and no item-to-total correlation score was lower than 0.4 . The factors explained $72.72 \%$ of the variance, which is above the recommended value of $60 \%$ [62]. Table 1 summarizes the variables' descriptions and the results of the CFA. Following Podsakoff et al. [68], the questionnaire was carefully prepared to reduce common method bias (CMB). Respondents were guaranteed total anonymity, and all information that could be exploited to backtrack to the respondents was removed. The existence of CMB was evaluated by using Harman's Single Test. The four factors that emerged from the exploratory factor analysis accounted for $72.72 \%$ of the variance in the data, with the first factor accounting for less than $50 \%$ of the total variance $(38.43 \%)$. Thus, CMB was not present.

Table 1. Variables' descriptions and loading factors.

\begin{tabular}{lccc}
\hline \multicolumn{1}{c}{ Constructs } & Mean & SD & $\begin{array}{c}\text { Loading } \\
\text { Factor }\end{array}$ \\
\hline *Organizational Learning Capability (OLC) (V.E $=70.09 \%) ;(\alpha=0.95)$ & & & \\
\hline Experimentation (OLC-E) & & & 0.86 \\
\hline $\begin{array}{l}\text { OLC-E1. In my organization, people receive support and encouragement when } \\
\text { presenting new ideas }\end{array}$ & 4.91 & 1.65 & 0.86 \\
\hline $\begin{array}{l}\text { OLC-E2. In my organization, initiative receives a favorable response, so people feel } \\
\text { encouraged to generate new ideas }\end{array}$ & 4.85 & 1.58 & \\
\hline Risk Taking (OLC-R) & 4.54 & 1.62 & 0.85 \\
\hline OLC-R3. In my organization, people are encouraged to take risk & 3.79 & 1.58 & 0.84 \\
\hline OLC-R4. In my organization, people often venture into unknown territory & & & \\
\hline Interaction with the external environment (OLC-I) & 4.21 & 1.78 & 0.83 \\
\hline $\begin{array}{l}\text { OLC-I5. In my organization, it is part of the work of all staff to collect, bring back, } \\
\text { and report information about what is going on outside the company }\end{array}$ & & & \\
\hline
\end{tabular}


Table 1. Cont.

\begin{tabular}{|c|c|c|c|}
\hline Constructs & Mean & SD & $\begin{array}{l}\text { Loading } \\
\text { Factor }\end{array}$ \\
\hline \multicolumn{4}{|l|}{${ }^{*}$ Organizational Learning Capability (OLC) (V.E = 70.09\%); $(\alpha=0.95)$} \\
\hline $\begin{array}{l}\text { OLC-I6. In my organization, there are systems and procedures for receiving, collating } \\
\text { and sharing information from outside the company }\end{array}$ & 3.90 & 1.73 & 0.83 \\
\hline $\begin{array}{l}\text { OLC-I7. In my organization, people are encouraged to interact with the environment: } \\
\text { competitors, customers, technological institutes, universities, suppliers, etc. }\end{array}$ & 4.48 & 1.69 & 0.82 \\
\hline \multicolumn{4}{|l|}{ Dialogue (OLC-D) } \\
\hline OLC-D8. In my organization, employees are encouraged to communicate & 5.07 & 1.59 & 0.80 \\
\hline $\begin{array}{l}\text { OLC-D9. In my organization, there is a free and open communication within my } \\
\text { work group }\end{array}$ & 5.38 & 1.47 & 0.77 \\
\hline OLC-D10. In my organization, managers facilitate communication & 5.26 & 1.60 & 0.77 \\
\hline OLC-D11. In my organization, cross-functional teamwork is a common practice & 4.84 & 1.70 & 0.73 \\
\hline \multicolumn{4}{|l|}{ Participative decision making (OLC-P) } \\
\hline $\begin{array}{l}\text { OLC-P12. Managers in my organization frequently involve employees in important } \\
\text { decisions }\end{array}$ & 4.64 & 1.76 & 0.67 \\
\hline OLC-P13. In my organization polices are significantly influenced by the employees'views & 4.33 & 1.67 & 0.63 \\
\hline OLC-P14. In my organization, people feel involved in main company decisions & 4.28 & 1.72 & 0.58 \\
\hline \multicolumn{4}{|l|}{${ }^{*}$ Knowledge Sharing (KS) $(\mathrm{V} . \mathrm{E}=75.53 \%) ;(\alpha=0.92)$} \\
\hline KS1. My organization provides relevant knowledge to our business partners & 4.57 & 1.58 & 0.92 \\
\hline KS2. My organization teams up with business partners to enhance interfirm learning & 4.52 & 1.71 & 0.90 \\
\hline $\begin{array}{l}\text { KS3. My organization and other business partners jointly organize job training to } \\
\text { enhance each other's knowledge }\end{array}$ & 3.91 & 1.72 & 0.88 \\
\hline $\begin{array}{l}\text { KS4. My organization and other business partners share successful experiences with } \\
\text { each other }\end{array}$ & 4.12 & 1.70 & 0.86 \\
\hline $\begin{array}{l}\text { KS5. My organization and other business partners share new knowledge and viewpoints } \\
\text { with each other }\end{array}$ & 4.13 & 1.64 & 0.77 \\
\hline \multicolumn{4}{|l|}{${ }^{*}$ Adoption of Environmental Practices (PRAC) $(\mathrm{V} . \mathrm{E}=66.89 \%) ;(\alpha=0.87)$} \\
\hline PRAC1. My organization buys ecological products & 4.27 & 1.69 & 0.86 \\
\hline $\begin{array}{l}\text { PRAC2. My organization has reduced the use of cleaning products that are harmful to } \\
\text { the environment }\end{array}$ & 4.76 & 1.71 & 0.88 \\
\hline PRAC3. My organization implements energy-saving practices & 5.39 & 1.44 & 0.82 \\
\hline PRAC4. My organization implements water-saving practices & 5.21 & 1.48 & 0.77 \\
\hline PRAC5. My organization implements the selective collection of solid residues & 5.79 & 1.45 & 0.72 \\
\hline \multicolumn{4}{|l|}{ *Product Innovation Performance (PIP) (V.E = 63,49\%); $(\alpha=0.89)$} \\
\hline \multicolumn{4}{|l|}{ Product innovation efficacy (PIP-EFFICA) } \\
\hline PIP-EFFICA1. Replacement of products being phased out & 4.81 & 1.56 & 0.84 \\
\hline $\begin{array}{l}\text { PIP-EFFICA2. Extension of product range within main product field through } \\
\text { new products }\end{array}$ & 5.28 & 1.50 & 0.83 \\
\hline PIP-EFFICA3. Extension of product range outside main product field & 4.63 & 1.64 & 0.83 \\
\hline PIP-EFFICA4. Development of environment-friendly products & 4.37 & 1.77 & 0.81 \\
\hline PIP-EFFICA5. Market share evolution & 5.17 & 1.54 & 0.73 \\
\hline PIP-EFFICA6. Opening of new markets abroad & 5.07 & 1.83 & 0.68 \\
\hline PIP-EFFICA7. Opening of new domestic target groups & 4.59 & 1.78 & 0.64 \\
\hline \multicolumn{4}{|l|}{ Product innovation efficiency (PIP-EFFICI) } \\
\hline PIP-EFFICI8. Average innovation project development time & 4.29 & 1.64 & 0.58 \\
\hline PIP-EFFICI9. Average number of working hours on innovation projects & 4.08 & 1.64 & 0.56 \\
\hline PIP-EFFICI10. Average cost per innovation project & 4.15 & 1.69 & 0.63 \\
\hline PIP-EFFICI11. Global degree of satisfaction with innovation project efficiency & 4.53 & 1.73 & 0.57 \\
\hline
\end{tabular}

Note: V.E = Variance explained; $\alpha=$ Cronbach's alpha; $\mathrm{SD}=$ standard deviation. 
Finally, we considered two firm-specific control variables, which refer to the firm's age and size. In this respect, "Age" denotes the natural logarithm of the firm's age, and "Firm's Size" denotes the number of employees $[69,70]$.

\subsection{Calibration}

Calibration is the process of classifying conditions from full membership to full non-membership. Using the method described by Ragin [71], we defined three different anchors to calibrate the data to establish the degree of membership in each score: 0.95 for full membership, 0.50 for membership ambiguity, and 0.05 for full non-membership. The transformation of the Likert scales into fuzzy sets is possible by calculating the average values of the items [72]. Since the measurement is a 7-point scale, we identify full non-membership, the crossover point, and full membership in Table 2.

Table 2. Calibration for causal conditions and outcome.

\begin{tabular}{|c|c|c|}
\hline Conditions and Outcome & Descriptive Statistics & Calibration $(0.95 ; 0.50 ; 0.05)$ \\
\hline Knowledge Sharing (KS) & $\mu=4.26, \sigma=1.45, \min =1.00, \max =7.00$ & $(6.2,4.4,1.6)$ \\
\hline $\begin{array}{l}\text { Adoption of environmental } \\
\text { practices (PRAC) }\end{array}$ & $\mu=5.08, \sigma=1.28, \min =1.00, \max =7.00$ & $(6.8,5.3,2.6)$ \\
\hline Firm type (FIRM TYPE) & Binary condition: $1=\mathrm{PLC} ; 0=\mathrm{GP}$ & No need \\
\hline Net exports (NET_EXP)(€) & $\begin{array}{l}\mu=6880761.39, \sigma=7315699.7, \min =-36678892.8 \\
\max =30949844.5\end{array}$ & $(19500000,6450000,4000000)$ \\
\hline Human resources costs (HRC) & $\mu=0.15, \sigma=0.10, \min =0.00, \max =0.72$ & $(0.31,0.13,0.025)$ \\
\hline $\begin{array}{l}\text { Organizational learning } \\
\text { capability (OLC) }\end{array}$ & $\begin{array}{l}\text { Generated by the function of "fuzzy and" (stands } \\
\text { for the mathematical logic operation in Boolean } \\
\text { algebra "conjunction") (E_OLC, R_OLC, I_OLC, } \\
\text { D_OLC, P_OLC) - no descriptives available for } \\
\text { uncalibrated values }\end{array}$ & $(0.95 ; 0.50 ; 0.05)$ \\
\hline $\begin{array}{l}\text { Sustainable product innovation } \\
\text { performance (PIP) }\end{array}$ & $\begin{array}{l}\text { Generated by the function of "fuzzy or" (stands } \\
\text { for the mathematical logic operation in Boolean } \\
\text { algebra "disjunction") (PIP_EFFICI, PIP_EFFICA) } \\
\text { - no descriptives available for uncalibrated values }\end{array}$ & $(0.95 ; 0.50 ; 0.05)$ \\
\hline
\end{tabular}

Note: Calibration for causal conditions and outcome: $\mu=$ mean, $\sigma=$ standard deviation, min $=$ minimum, $\max =$ maximum.

We adjusted the cut-values depending on the number of items for each variable and its statistics [73].

\section{Results}

\subsection{Structural Equation Modeling}

We used SEM to test hypotheses H1-H6. To test H6, a joint multigroup moderation analysis was performed with SEM, with a distinction being made between public limited companies $(\mathrm{N}=222)$ and general partnerships $(\mathrm{N}=127)$. The firm's organizational structure and its type can affect the adoption of environmental practices and sustainable PIP. The indices show an adequate overall fir for model 1 and 2A/2B. Table 3 presents the absolute (Model 1: $\chi^{2} / \mathrm{df}=1.658$, RMSEA $=0.043$; Model 2A $/ 2 \mathrm{~B}$ : $\chi^{2} / \mathrm{df}=1.538$, RMSEA $=0.039$ ) and incremental (Model 1: CFI = 0.961, TLI = 0.955; Model 2A/2B:CFI $=0.939, \mathrm{TLI}=0.929)$ indices that factor in the recommended values for a good fit, as in Hair et al. [62].

We assessed the overall fit of the measurement model following the guidelines in Hair et al. [62], who used the CFA to assess the psychometric properties of the constructs. The CFA shows an adequate fit (Table 1).

Table 3 shows the results for the hypotheses. Hypothesis 1 concerns the relation between NET EXP and PRAC. The results show that a significant effect on capacity is supported in model 1 . Also, the results confirm that NET EXP has significantly positive effects on PRAC in model 2A (PLC: $\beta=0.094$, $p<0.05)$ and model $2 \mathrm{~B}(\mathrm{GP}: \mathrm{B}=0.050, p<0.10)$. 
Table 3. Structural models' fit and results.

\begin{tabular}{|c|c|c|c|c|c|c|c|}
\hline & Paths & Estimate & SE & CR & $\mathbf{P}$ & \multicolumn{2}{|c|}{ Results } \\
\hline \multicolumn{8}{|l|}{ Model 1: } \\
\hline $\mathrm{H} 1(+)$ & $\begin{array}{l}\mathrm{PRAC} \leftarrow \mathrm{NET} \\
\text { EXP }\end{array}$ & 0.074 & 0.030 & 2.419 & 0.016 & \multicolumn{2}{|c|}{ Supported } \\
\hline $\mathrm{H} 2(+)$ & $\mathrm{PRAC} \leftarrow \mathrm{HRC}$ & 0.446 & 0.538 & 0.829 & 0.407 & \multirow{4}{*}{\multicolumn{2}{|c|}{$\begin{array}{l}\text { Not Supported } \\
\text { Supported } \\
\text { Supported } \\
\text { Supported }\end{array}$}} \\
\hline $\mathrm{H} 3(+)$ & $\mathrm{PRAC} \leftarrow \mathrm{OLC}$ & 0.423 & 0.064 & 6.584 & $* * *$ & & \\
\hline $\mathrm{H} 4(+)$ & $\mathrm{PRAC} \leftarrow \mathrm{KS}$ & 0.258 & 0.056 & 4.629 & $* * *$ & & \\
\hline $\mathrm{H} 5(+)$ & $\mathrm{PIP} \leftarrow \mathrm{PRAC}$ & 0.769 & 0.096 & 8.013 & $* * *$ & & \\
\hline \multicolumn{8}{|l|}{$\begin{array}{l}\text { Model 2: Firm type (H6) } \\
\text { Model 2A: PLC }\end{array}$} \\
\hline $\mathrm{H} 1(+)$ & $\begin{array}{l}\text { PRAC } \leftarrow \text { NET } \\
\text { EXP }\end{array}$ & 0.094 & 0.046 & 2.027 & 0.043 & \multicolumn{2}{|c|}{ Supported } \\
\hline $\mathrm{H} 2(+)$ & $\mathrm{PRAC} \leftarrow \mathrm{HRC}$ & 0.029 & 0.742 & 0.039 & 0.969 & \multirow{4}{*}{\multicolumn{2}{|c|}{$\begin{array}{c}\text { Not Supported } \\
\text { Supported } \\
\text { Supported } \\
\text { Supported }\end{array}$}} \\
\hline $\mathrm{H} 3(+)$ & $\mathrm{PRAC} \leftarrow$ OLC & 0.410 & 0.088 & 4.682 & $* * *$ & & \\
\hline $\mathrm{H} 4(+)$ & $\mathrm{PRAC} \leftarrow \mathrm{KS}$ & 0.284 & 0.073 & 3.916 & $* * *$ & & \\
\hline $\mathrm{H} 5(+)$ & $\mathrm{PIP} \leftarrow \mathrm{PRAC}$ & 0.647 & 0.105 & 6.136 & $* * *$ & & \\
\hline \multicolumn{8}{|l|}{ Model 2B: GP } \\
\hline $\mathrm{H} 1(+)$ & $\begin{array}{l}\mathrm{PRAC} \leftarrow \mathrm{NET} \\
\text { EXP }\end{array}$ & 0.050 & 0.031 & 1.612 & 0.107 & \multicolumn{2}{|c|}{ Supported } \\
\hline $\mathrm{H} 2(+)$ & $\mathrm{PRAC} \leftarrow \mathrm{HRC}$ & 0.977 & 0.608 & 1.608 & 0.108 & \multirow{4}{*}{\multicolumn{2}{|c|}{$\begin{array}{l}\text { Supported } \\
\text { Supported } \\
\text { Supported } \\
\text { Supported }\end{array}$}} \\
\hline $\mathrm{H} 3(+)$ & $\mathrm{PRAC} \leftarrow$ OLC & 0.368 & 0.084 & 4.367 & $* * *$ & & \\
\hline $\mathrm{H} 4(+)$ & $\mathrm{PRAC} \leftarrow \mathrm{KS}$ & 0.220 & 0.072 & 3.056 & 0.002 & & \\
\hline $\mathrm{H} 5(+)$ & $\mathrm{PIP} \leftarrow \mathrm{PRAC}$ & 1.113 & 0.234 & 4.762 & $* * *$ & & \\
\hline & $X^{2}$ & Df & $p$-value & $\mathrm{X}^{2} / \mathrm{df}$ & CFI & TLI & RMESA \\
\hline $\begin{array}{l}\text { Measurement Model Summary: } \\
\text { First Order: KS \& PRAC }\end{array}$ & 281.727 & 34 & 0.000 & 8.286 & 0.905 & 0.874 & 0.042 \\
\hline $\begin{array}{l}\text { Measurement Model Summary: } \\
\text { Second Order: OLC }\end{array}$ & 357.042 & 72 & 0.000 & 4.959 & 0.934 & 0.917 & 0.041 \\
\hline Second Order: PIP & 262.569 & 43 & 0.000 & 6.106 & 0.903 & 0.876 & 0.040 \\
\hline Structural Model 1 Summary & 953.304 & 575 & 0.000 & 1.658 & 0.961 & 0.955 & 0.043 \\
\hline $\begin{array}{l}\text { Structural Models 2A/2B } \\
\text { Summary }\end{array}$ & 1769.018 & 1150 & 0.000 & 1.538 & 0.939 & 0.929 & 0.039 \\
\hline
\end{tabular}

Hypothesis 2 refers to the relation between HRC and PRAC. The results confirm that HRC has no effect on PRAC in model 1 and model 2A (PLC). However, the results indicate that HRC has significantly positive effects on PRAC in model $2 B(G P: B=0.977, p<0.10)$.

Further, the findings show that OLC has significantly positive effects on PRAC (H3) in models 1 $(B=0.423, p<0.001), 2 \mathrm{~A}(\beta=0.410, p<0.001)$ and $2 \mathrm{~B}(\beta=0.368, p<0.001)$.

Likewise, the results support the relation between KS and PRAC (H4) in models $1(B=0.258$, $p<0.001), 2 \mathrm{~A}(\mathrm{~B}=0.284, p<0.001)$, and $2 \mathrm{~B}(\mathrm{~B}=0.220, p<0.05)$.

The findings show that NET EXP has a significant effect on PRAC in the three models (H1). However, for H2, the results show only significantly positive effects in the 2B model (GP). The results show significantly positive effects between OLC, KS, and PRAC in the three models ( $\mathrm{H} 3$ and $\mathrm{H} 4$ ). Finally, the results support $\mathrm{H} 5$ in the three models. $\mathrm{H} 6$ is partially confirmed because GPs make greater investment efforts in HRC for the development and adoption of PRAC. Therefore, PRAC is a relevant antecedent of PIP, and GPs improve HRC for PIP. 


\subsection{Fuzzy-Set Qualitative Comparative Analysis}

To address the configurations that lead to PIP (H7) or its absence (H8), we followed the recommendations of Ragin [71] and Fiss [54]. The fsQCA method is used to define alternative configurations of conditions, equifinality, and asymmetry [54] that lead to PIP or its absence. The fsQCA method uses the same variables as the SEM analysis.

The condition's degree of necessity indicates its impact on achieving the outcome [74]. Regarding PIP, no conditions meet the threshold in the literature (consistency of over 0.80 [75]); thus, there are no necessary conditions for PIP. Regarding $\sim$ PIP ( refers to the absence of), there is a single necessary condition: OLC. Such results demonstrate asymmetry.

The condition's degree of sufficiency shows the extent of its relation to the explanation of the outcome [74]. The sufficient sets are configurations of several conditions that lead to the outcome variable. The PIP and the $\sim$ PIP consistency levels of the two intermediate solutions meet the consistency threshold of at least 0.75 [76,77], and the solutions' coverage levels are within the suggested limits of 0.25-0.90 [78]. Regarding PIP, there are four causal combinations in the solution. Considering $\sim$ PIP, there are two causal combinations in the solution (Table 4). Such results demonstrate there are alternative configurations of conditions leading to the same outcomes. The causal configurations in the solutions present core and peripheral conditions for PIP and PIP for all SMEs [61] (Table 4). The core conditions are the ones included in both the parsimonious and intermediate solutions, while the peripheral conditions are only part of the intermediate solution [74].

Table 4. Intermediate solutions for PIP and $\sim$ PIP.

\begin{tabular}{|c|c|c|c|c|c|c|c|c|c|}
\hline \multicolumn{10}{|c|}{ Intermediate Solution (PIP) } \\
\hline \multicolumn{10}{|c|}{ Model: PIP = f (FIRM TYPE, NET EXP, HRC, OLC, KS, PRAC) } \\
\hline \multirow[t]{2}{*}{ Configurations } & \multirow{2}{*}{$\begin{array}{l}\text { FIRM } \\
\text { TYPE }\end{array}$} & \multirow{2}{*}{$\begin{array}{l}\text { NET } \\
\text { EXP }\end{array}$} & \multirow{2}{*}{ HRC } & \multirow[t]{2}{*}{ OLC } & \multirow[t]{2}{*}{ KS } & \multirow[t]{2}{*}{ PRAC } & \multicolumn{2}{|c|}{ Coverage } & \multirow{2}{*}{ Consistency } \\
\hline & & & & & & & Raw & Unique & \\
\hline 1 & & & & & & $\bullet$ & 0.728123 & 0.351214 & 0.795770 \\
\hline 2 & O & & & $\bullet$ & & & 0.200603 & 0.011803 & 0.896009 \\
\hline 3 & & & $\bullet$ & $\bullet$ & & & 0.328973 & 0.019606 & 0.921915 \\
\hline 4 & 0 & O & O & & & & 0.170574 & 0.018461 & 0.811225 \\
\hline \multicolumn{5}{|c|}{ Overall solution coverage: 0.795650} & & \multicolumn{4}{|c|}{ Overall solution consistency: 0.785965} \\
\hline \multicolumn{10}{|c|}{ IntermediateSolution( PIP) } \\
\hline \multicolumn{10}{|c|}{ Model: PIP = f(FIRMTYPE,NETEXP,HRC,OLC,KS,PRAC) } \\
\hline \multirow[t]{2}{*}{ Configurations } & $\begin{array}{l}\text { FIRM } \\
\text { TYPE }\end{array}$ & $\begin{array}{l}\text { NET } \\
\text { EXP }\end{array}$ & HRC & OLC & KS & PRAC & \multicolumn{2}{|c|}{ Coverage } & \multirow[t]{2}{*}{ Consistency } \\
\hline & & & & & & & Raw & Unique & \\
\hline 1 & 0 & & $\bullet$ & 0 & & 0 & 0.172478 & 0.023613 & 0.811683 \\
\hline 2 & & 0 & $\bullet$ & 0 & & 0 & 0.432359 & 0.283494 & 0.818233 \\
\hline \multicolumn{6}{|c|}{ Overallsolutioncoverage: 0.455971} & \multicolumn{4}{|c|}{ Overallsolutionconsistency:0.816442 } \\
\hline
\end{tabular}

\section{Discussion and Conclusions}

The importance of sustainability in business and society has been emphasized by many scholars. The development of sustainable innovations represents a driving force for the creation of new job opportunities, regional/national/international competitiveness, and sustainable and social growth. 
Three pillars (economic, social, and environment development) play a significant role in the decision to develop new sustainable innovations.

However, few studies about SMEs have examined the three pillars together to increase sustainable innovations. The previous arguments emphasize that more research is needed to fully comprehend the interrelated nature of firms' innovation dynamics and sustainability [2,3]. In addition, this study offers the opportunity to understand whether SMEs with different legal forms behave differently in terms of sustainable innovations.

The aim of this study is to answer three research questions: How are economic, social, and environmental aspects balanced in innovation activities? What is needed to make the triple bottom line approach more effective (e.g., new communications, new human resource practices, and knowledge sharing management methods)? Does a firm's legal form (e.g., public limited companies versus general partnerships) affect its commitment toward sustainable innovation?

Drawing on the TBL, this study examined the impact of two economic factors (NET EXPORTS and HRC) and two social factors (OLC and KS) on PRAC and sustainable PIP.

We use a mixed methods approach $[79,80]$, and the quantitative results show the following. Our results indicate that NET EXP is indeed positively associated with PRAC (model 1, model 2A: PLC; model 2B: GP). Hence, the SMEs with positive outcomes from internationalism are better prepared to develop sustainable PIP (PLC or GP). Our results also indicate that HRC of GP SMEs exerts a positive influence on PRAC (model 2B). Therefore, investments in HR are very important within GP SMEs and are not easily transmissible. Here, investments in HR are more relevant than they are in other SME types because social responsibility is often from the same partners. Thus, the managers engage in PRAC, and they use financial resources to foster an employee's knowledge, creativity, and motivation [81]. Hence, in addition to HR being a valuable resource, it is also a strategic resource that primes GPs for the adoption of PRAC [8].

Following the TBL, the results show that the second pillar, social factors (OLC and KS), has a positive impact on the third pillar (environment development). Therefore, OLC and KS are the most important resources for developing PRAC in any firm type [8]. New meetings and knowledge exchanges lead to new practices, new environments, new products, and, consequently, sustainable societies. Hence, social development is the cornerstone of sustainable PIP.

Finally, our research model shows that the adoption of PRAC is the third pillar for sustainable PIP. In this line, our results show that the adoption PRAC can lead to sustainable PIP. Overall, the main finding is that our models indicate that environmental factors are the key to sustainable PIP in any SME.

In sum, this study proposes a full research model that shows how the three pillars of the TBL may be aligned to generate new challenges in terms of sustainable PIP in SMEs and sustainable development.

According to the qualitative approach, no necessary conditions exist for the realization of the outcome, but $\sim$ OLC is a necessary condition for $\sim$ PIP. Such findings show that the lack of OLC contributes to $\sim$ PIP. Alternative configurations exist that lead to sustainable PIP and $\sim$ PIP. Regarding the number of configurations, the results show that more configurations (4) lead to sustainable PIP than lead to its absence (2). Such evidence indicates the existence of more pathways that lead to PIP than lead to its absence; this is important for SME managers to know. These results support H7 and $\mathrm{H} 8$ and demonstrate equifinality. Configuration 1 leading to PIP is exclusively provided by PRAC, illustrating the relevance of adopting environmental practices.

Both configurations leading to $\sim$ PIP share HRC, $\sim \mathrm{OLC}$, and $\sim \mathrm{PRAC}$, meaning that high HRC and the absence of OLC and PRAC are relevant conditions for $\sim$ PIP.

This paper shows the alignment of the pillars in the TBL and its pathways for sustainable PIP in Portuguese SMEs. These findings reinforce the results of the SEM analysis performed for H6. A firm's type is not a core condition for sustainable PIP or $\sim$ PIP, indicating that the process lacks importance. Additionally, KS is not relevant for PIP and $\sim$ PIP, questioning the previous literature. The results 
from the quantitative and qualitative analyses underline the effects of economic factors, social factors, and environmental practices on sustainable PIP.

\subsection{Theoretical and Practical Implications}

There are several theoretical and practical implications arising from our results. We provide a double theoretical approach (quantitative and qualitative) and double empirical approach (for managers and governments). We provide support for the TBL within the context of sustainable PIP and confirm the importance of several resources and capabilities within the three pillars for SMEs' sustainable PIP. We offer a novel theoretical model of sustainable PIP in SMEs to the academic and the business worlds. SMEs can contribute to sustainable development and thus respond to the great global challenges of sustainable development such as; a) climate change, b) greater investment for human development, and c) cooperation and creation of networks to share knowledge about ecological practices and policies among companies. Therefore, our model presents a real solution, available to academics and managers, showing how SMEs can develop new products that contribute to the quality and conservation of the environment, the social and human development and sustainable economic growth [82,83].

Kraus et al. [61] argue that the use of fsQCA provides the appropriate guidance to the development of business models based on the antecedents of innovation. The authors consider that the fsQCA technique proves to be adequate in the context of configurational paths leading to performance of business model based on innovation, such as entrepreneurial activities and capabilities, since the technique has a promising future from both theoretical and empirical views. Therefore, this study makes a relevant contribution to the field of business models based on innovation providing the antecedents and paths that lead to sustainable PIP. Moreover, the application of fsQCA reinforces the results obtained from the use of the quantitative technique (SEM). Thus, we address a relevant business phenomenon from a thorough mixed methods view contributing to understand the sustainability of PIP in SMEs.

Specifically, our findings indicate that international activities are always relevant to the implementation of PRAC. The exploitation of new opportunities can help SMEs achieve sustainable development. Our findings show that HR investments are important for GPs. Here, SME managers focus on HR practices because they may more easily get to know their employees. Currently, firms are already beginning to show their concern in this regard. Max De Pree-founder and CEO of Herman Miller, a Fortune 500 company-completely restructured and invested in the organization on the basis of human values. De Pree believes that employees are the source of transformation that every company needs to face changes and generate new sustainable innovations. De Pree also believes that employees can more easily achieve the mission, vision, and sustainability values of the company. Sustainable innovative success is much more likely to be achieved by placing more focus on human and social values than other material resources. Along these lines, the Great Place to Work Institute (GPTW) indicates that the best companies to work for are those that foster relationships to improve the trust between leaders and employees or among the employees themselves, and they invest a great deal in HRM. Furthermore, the second pillar of social development indicates that OLC at the firm level and $\mathrm{KS}$ at the interorganizational level can generate new resources for implementing sustainable PRAC in SMEs.

For SME managers, our findings highlight the need to focus on aligning the pillars of the TBL for sustainable PIP. We propose the integration of external activities, such as EXPORT and KS, with internal activities, such as HR, OLC, and PRAC, for sustainable PIP development. Thus, the overall results of the study point to the importance of adopting the TBL as a way to better measure firms' strategic resources and capabilities by emphasizing ethical business behavior for sustainable PIP.

From a global perspective, governments should focus on promoting and formulating new regulations and cutting taxes to generate sustainable innovations. From an internal perspective of SMEs, managers may choose to implement the Eco-Management and Audit Scheme (EMAS) or 
other software for environmental regulation. This can be done by providing adequate financing, training, and networking between firms and countries.

Finally, we offer five relevant practical recommendations and implementation guidelines for SMEs:

1. International business for sustainable innovation:

- The willingness of experts to help with new international activities.

- Presence in congresses and international fairs.

- Continuous vigilance to detect new investment and export opportunities.

- Joint innovation projects with foreign partners.

2. Investment in and development of new human resource practices for sustainable innovation:

- Courses and training in sustainable development.

- Encouragement of employee trust and motivation.

- Creation of a culture that encourages sustainable development.

- The build-up of norms that encourage sustainable development.

3. Fast Organizational Learning Capability for sustainable innovation:

- Climate for learning and experimentation.

- Encouragement to take risks in the design of new sustainable products.

- Implementation of environmental information collection systems to determine the needs of consumers.

- Teamwork and effective communication.

- Involvement of employees in important decisions.

4. Knowledge Sharing for sustainable innovation:

- Reinforcement of information sharing with new alliances and business partners.

- Creation of a culture that encourages knowledge sharing.

- Encouragement of employees to share their knowledge and ideas with those outside partners.

- $\quad$ Support for business networking (e.g., LinkedIn).

- Use of performance management systems to promote voice and knowledge sharing.

- Creation of incentives (e.g., promotion, bonus, higher salary) to facilitate knowledge sharing.

5. Adoption of Environmental practices for sustainable innovation:

- Design of a code of environmental ethics for all members of the company and its business partners.

- Implementation of energy saving practices.

- Implementation of reverse logistics practices.

- Development of productive activity with ecological products.

- Advanced training in eco-innovation and social and environmental needs.

\subsection{Limitations and Future Research}

Our results should be interpreted within the possible limitations of the study. Despite the lack of evidence of $\mathrm{CMB}$, the self-reported measures certainly have their weaknesses, since they measure the level of OLC, KS, PRAC, and PIP on the basis of managers' perceptions. However, this paper uses objective data with economic variables such as NET EXP and HRC.

In addition, future researchers could implement additional measures to evaluate economic development such as ROA, ROE, sales, and economic growth. Furthermore, the data are confined to firms located in one particular national context. 
Considering the time and cost limitations, a sample size of 349 is small (the response rate was $5.1 \%$ ), but the sample it generated is representative of Portuguese SMEs. However, the extent to which they can be generalized to other geographical contexts, large companies, and institutional settings remains questionable. To follow up on our findings and help us better understand our results, future studies could analyze the effects of other variables within the three dimensions of the TBL for sustainable development (creativity, technology, etc.). We argue that addressing such dimensions of sustainable development is a challenge worth pursuing by using the triple bottom line approach [8]. Such influences should be explored at the individual, organizational, and interorganizational level. Longitudinal studies that incorporate several levels of analysis could provide evidence of the causal relations and interactions among the dimensions of the TBL. In addition, future studies could focus on examining sectorial effects, since firms from certain industries are exposed to more opportunities for PRAC than are firms from other industries.

Our study can serve as a useful guide for the design of future research on the development of sustainable innovations on the basis of the TBL. Our study analyzed SMEs because they represent $95 \%$ of the businesses in the world. In this sense, we propose that they are the best agents of change, transformation, development of sustainable innovations, and, therefore, global sustainable growth. Therefore, among SMEs, we analyzed whether there may be differences in the development of sustainable innovations due to their legal form. However, it would be very interesting to determine whether our results differ from the results of studying sustainable innovation in large companies. The application of our research model in the context of large companies may help to answer different research questions: Is it easier for large companies to access financing for sustainable innovations? Do large companies have more access to business partners for the development of sustainable innovations? Do large companies have more environmental advantages in national and international policies for the development of sustainable innovations? The results of investigating these three research questions will be very interesting for future research because they can be compared with our results obtained for SMEs.

It would also be interesting to analyze the influence of context-dependent institutional pressures, such as government regulation or consumer sensitivity for sustainable development. Finally, future research could undertake an international comparison to test for the consistency of our findings across countries and/or cultures and also uncover new sources of environmental development for sustainable PIP in SMEs.

Author Contributions: Conceptualization, L.M.-P., C.C. and J.G.; methodology, L.M.-P., C.C. and J.G.; software, L.M.-P. and C.C.; validation, L.M.-P. and C.C.; formal analysis, L.M.-P. and C.C.; investigation, L.M.-P., C.C. and J.G.; data curation, L.M.-P. and C.C; writing - original draft preparation, L.M.-P.; writing-review and editing, L.M.-P., C.C. and J.G.; visualization, L.M.-P., C.C. and J.G.; supervision, C.C. and J.G.; project administration, C.C. and J.G.; funding acquisition, C.C. and J.G.

Funding: This research was funded by "Fundação para a Ciência e Tecnologia"—Portugal (FCT), grant number UID/SOC/04521/2019; "Agencia Estatal de Investigación" (AEI) and the "Fondo Europeo de Desarrollo Regional" (FEDER), grant number ECO16-76876-R-AEI/FEDER, UE; and Castile and Leon Regional Ministry of Education in Spain, grant number SA027U16.

Conflicts of Interest: The authors declare no conflict of interest.

\section{References}

1. Dahlsrud, A. How Corporate Social Responsibility is defined: An Analysis of 37 definitions. Corp. Soc. Responsib. Environ. Manag. 2008, 15, 1-13. [CrossRef]

2. Hart, S.L.; Milstein, M.B. Creating Sustainable Value. Acad. Manag. Exec. 2003, 17, 56-67. [CrossRef]

3. Longoni, A.; Cagliano, R. Sustainable Innovativeness and the Triple Bottom Line: The Role of Organizational Time Perspective. J. Bus. Ethics 2018, 151, 1097-1120. [CrossRef]

4. Ayyagari, M.; Demirgü-Kunt, A.; Maksimovic, V. Small vs. Young Firms across the World - Contribution to Employment, Job Creation, and Growth; Policy Research Working Paper 5631; World Bank: Washington, DC, USA, 2011. 
5. Testa, F.; Gusmerottia, N.M.; Corsini, F.; Passetti, E.; Iraldo, F. Factors Affecting Environmental Management by Small and Micro Firms: The Importance of Entrepreneurs' Attitudes and Environmental Investment. Corp. Soc. Responsib. Environ. Manag. 2016, 23, 373-385. [CrossRef]

6. Schramm, C. All Entrepreneurship is Social. Stanf. Soc. Innov. Rev. 2010, 7, 20-22.

7. Cohen, B.; Smith, B.; Mitchell, R. Toward a Sustainable Conceptualization of Dependent Variables in Entrepreneurship Research. Bus. Strategy Environ. 2008, 17, 107-119. [CrossRef]

8. Glavas, A.; Mish, J. Resources and Capabilities of Triple Bottom Line Firms: Going over Old or Breaking New Ground? J. Bus. Ethics 2015, 127, 623-642. [CrossRef]

9. Dibrell, C.; Craig, J.B.; Kim, J.; Johnson, A.J. Establishing How Natural Environmental Competency, Organizational Social Consciousness, and Innovativeness Relate. J. Bus. Ethics 2015, 127, 591-605. [CrossRef]

10. Kennedy, E.B.; Marting, T.A. Biomimicry Streamlining the Front End of Innovation for Environmentally Sustainable Products. Res.-Technol. Manag. 2016, 59, 40-47. [CrossRef]

11. Wagner, M. Innovation and Competitive Advantages from the Integration of Strategic Aspects with Social and Environmental Management in European Firms. Bus. Strategy Environ. 2009, 18, 291-306. [CrossRef]

12. Hall, J.; Wagner, M. Integrating Sustainability into Firms' Processes: Performance Effects and the Moderating Role of Business Models and Innovation. Bus. Strategy Environ. 2012, 21, 183-196. [CrossRef]

13. Schaltegger, S.; Hansen, E.G.; Lüdeke-Freund, F. Business Models for Sustainability: Origins, Present Research, and Future Avenues. Organ. Environ. 2016, 29, 3-10. [CrossRef]

14. Gasbarro, F.; Annunziata, E.; Rizzi, F.; Frey, M. The Interplay between Sustainable Entrepreneurs and Public Authorities: Evidence from Sustainable Energy Transitions. Organ. Environ. 2017, 30, 226-252. [CrossRef]

15. Vollenbroek, F.A. Sustainable Development and the Challenge of Innovation. J. Clean. Prod. 2002, 10, $215-223$. [CrossRef]

16. Wu, G.C. Effects of Socially Responsible Supplier Development and Sustainability-Oriented Innovation on Sustainable Development: Empirical Evidence from SMEs. Corp. Soc. Responsib. Environ. Manag. 2017, 24, 661-675. [CrossRef]

17. Hitt, M.A.; Ireland, R.D.; Hoskisson, R.E. Strategic Management: Competitiveness and Globalization, 7th ed.; Thomson South-Western: Mason, OH, USA, 2007.

18. Attig, N.; Boubakri, N.; El Ghoul, S.; Guedhami, O. Firm Internationalization and Corporate Social Responsibility. J. Bus. Ethics 2016, 134, 171-197. [CrossRef]

19. Ayuso, S.; Roca, M.; Arevalo, J.A.; Aravind, D. What Determines Principle-Based Standards Implementation? Reporting on Global Compact adoption in Spanish Firms. J. Bus. Ethics 2016, 133, 553-565. [CrossRef]

20. Bansal, P. Evolving Sustainability: A Longitudinal Study of Corporate Sustainable Development. Strateg. Manag. J. 2005, 26, 197-218. [CrossRef]

21. Strike, V.M.; Gao, J.; Bansal, P. Being Good while Being Bad: Social Responsibility and International Diversification of US Firms. J. Int. Bus. Stud. 2006, 37, 850-862. [CrossRef]

22. Hoppmann, J. The Role of Interfirm Knowledge Spillovers for Innovation in Mass-Produced Environmental Technologies: Evidence from the Solar Photovoltaic Industry. Organ. Environ. 2018, 31, 3-24. [CrossRef]

23. Celma, D.; Martínez-Garcia, E.; Coenders, G. Corporate Social Responsibility in Human Resource Management: An Analysis of Common Practices and their Determinants in Spain. Corp. Soc. Responsib. Environ. Manag. 2014, 21, 82-99. [CrossRef]

24. Gratton, L.; Ghoshal, S. Managing Personal Human Capital: New Ethos for the 'Volunteer'employee. Eur. Manag. J. 2003, 21, 1-10. [CrossRef]

25. Muñoz-Pascual, L.; Galende, J. The Impact of Knowledge and Motivation Management on Creativity: Employees of Innovative Spanish Companies. Empl. Relat. 2017, 39, 732-752. [CrossRef]

26. Barney, J.B. Looking Inside for Competitive Advantage. Acad. Manag. Exec. 1995, 9, 49-61. [CrossRef]

27. Jérez-Gómez, P.; Cespedes-Lorente, J.; Valle-Cabrera, R. Organizational Learning and Compensation Strategies: Evidence from the Spanish Chemical Industry. Hum. Resour. Manag. 2005, 44, 279-299. [CrossRef]

28. Jaw, B.S.; Liu, W. Promoting Organizational Learning and Self-Renewal in Taiwanese Companies: The Role of HRM. Hum. Resour. Manag. 2003, 42, 223-241. [CrossRef]

29. Argote, L. Organizational Learning: Creating, Retaining and Transferring Knowledge, 2nd ed.; Springer: Media, PA, USA, 2013.

30. Lichtenthaler, U. Absorptive Capacity, Environmental Turbulence, and the Complementarity of Organizational Learning Processes. Acad. Manag. J. 2009, 52, 822-846. [CrossRef] 
31. Chiva, R.; Alegre, J.; Lapiedra, R. Measuring Organizational Learning Capability Among the Workforce. Int. J. Manpow. 2007, 28, 224-242. [CrossRef]

32. Valaei, N.; Rezaei, S.; Wan-Ismail, W.K. Examining Learning Strategies, Creativity, and Innovation at SMEs using fuzzy set Qualitative Comparative Analysis and PLS Path Modeling. J. Bus. Res. 2017, 70, 224-233. [CrossRef]

33. Shih, S.C.; Hsu, S.H.Y.; Zhu, Z.; Balasubramanian, S.K. Knowledge Sharing, a Key Role in the Downstream Supply Chain. Inf. Manag. 2012, 49, 70-80. [CrossRef]

34. Bhatti, W.A.; Larimo, J.; Carrasco, I. Strategy's Effect on Knowledge Sharing in Host Country Networks. J. Bus. Res. 2016, 69, 4769-4774. [CrossRef]

35. Boer, N.I.; Berends, H.; Van Baalen, P. Relational Models for Knowledge Sharing Behavior. Eur. Manag. J. 2011, 29, 85-97. [CrossRef]

36. Cheng, J.H. Inter-Organizational Relationships and Information Sharing in Supply Chains. Int. J. Inf. Manag. 2011, 31, 374-384. [CrossRef]

37. Liu, Y.; Li, Y.; Shi, L.H.; Liu, T. Knowledge Transfer in Buyer-Supplier Relationships: The role of transactional and relational governance mechanisms. J. Bus. Res. 2017, 78, 285-293. [CrossRef]

38. Kianto, A.; Sáenz, J.; Aramburu, N. Knowledge-Based Human Resource Management Practices, Intelectual Capital and Innovation. J. Bus. Res. 2017, 81, 11-20. [CrossRef]

39. Xie, X.; Fang, L.; Zeng, S.; Huo, J. How does knowledge inertia affect firms' product innovation? J. Bus. Res. 2016, 69, 1615-1620. [CrossRef]

40. Gavronski, I.; Ferrer, G.; Paiva, E.L. ISO 14001 Certification in Brazil: Motivations and Benefits. J. Clean. Prod. 2008, 16, 87-94. [CrossRef]

41. Fernández-Viñé, M.B.; Gómez-Navarro, T.; Capuz-Rizo, S.F. Eco-efficiency in the SMEs of Venezuela. Current Status and Future Perspectives. J. Clean. Prod. 2010, 18, 736-746. [CrossRef]

42. Ramanathan, R.; Black, A.; Nath, P.; Muyldermans, L. Impact of Environmental Regulations on Innovation and Performance in the UK Industrial Sector. Manag. Decis. 2010, 48, 1493-1513. [CrossRef]

43. Aragón-Correa, J.A.; Hurtado-Torres, N.; Sharma, S.; García-Morales, V.J. Environmental Strategy and Performance in Small Firms: A Resource-Based Perspective. J. Environ. Manag. 2008, 86, 88-103. [CrossRef]

44. Chan, E.S.W.; Hawkins, R. Attitude Towards EMSs in an International Hotel: An Exploratory Case Study. Int. J. Hosp. Manag. 2010, 29, 641-651. [CrossRef]

45. Mohamed, S.T. The Impact of ISO 14,000 on developing World Businesses. Renew. Energy 2001, 23, 579-584. [CrossRef]

46. Fresner, J.; Engelhardt, G. Experiences with Integrated Management Systems for Two Small Companies in Austria. J. Clean. Prod. 2004, 12, 623-631. [CrossRef]

47. Amabile, T.M.; Conti, R.; Coon, H.; Lazenby, J.; Herron, M. Assessing the Work Environment for Creativity. Acad. Manag. J. 1996, 39, 1154-1184.

48. Ngo, L.V.; O'Cass, A. Innovation and Business Success: The Mediating Role of Customer Participation. J. Bus. Res. 2013, 66, 1134-1142. [CrossRef]

49. Chang, C.H. The Determinants of Green Product Innovation Performance. Corp. Soc. Responsib. Environ. Manag. 2016, 23, 65-76. [CrossRef]

50. Alegre, J.; Lapiedra, R.; Chiva, R. A Measurement Scale for Product Innovation Performance. Eur. J. Innov. Manag. 2006, 9, 333-346. [CrossRef]

51. Kyffin, S.; Gardien, P. Navigating the Innovation Matrix: An Approach to Designled Innovation. Int. J. Des. 2009, 3, 57-69.

52. Gupta, S.; Malhotra, N. Marketing Innovation: A Resource-Based View of International and Local Firms. Mark. Intell. Plan. 2013, 31, 111-126. [CrossRef]

53. Curado, C.; Muñoz-Pascual, L.; Galende, J. Antecedent to Innovation Performance in SMEs: A Mixed Methods Approach. J. Bus. Res. 2018, 89, 206-215. [CrossRef]

54. Fiss, P.C. Building Better Causal Theories: A Fuzzy Set Approach to Typologies in Organization Research. Acad. Manag. J. 2011, 54, 393-420. [CrossRef]

55. Osabutey, E.L.C.; Jin, Z. Factors Influencing Technology and Knowledge Transfer: Configurational Recipes for Sub-Saharan Africa. J. Bus. Res. 2016, 69, 5390-5395. [CrossRef]

56. Ozkan-Canbolat, E.; Beraha, A. Evolutionary Knowledge Games in Social Networks. J. Bus. Res. 2016, 69, $1807-1811$. [CrossRef] 
57. Cragun, D.; Pal, T.; Vadaparampil, S.; Baldwin, J.; Hampel, H.; DeBate, R. Qualitative Comparative Analysis: A Hybrid Method for Identifying Factors Associated with Program Effectiveness. J. Mix. Methods Res. 2016, 10, 251-272. [CrossRef]

58. Oyemomi, O.; Liu, S.; Neaga, I.; Alkhuraiji, A. How Knowledge Sharing and Business Process Contribute to Organizational Performance: Using the fsQCA Approach. J. Bus. Res. 2016, 69, 4725-5546. [CrossRef]

59. Berkovich, I. Beyond Qualitative/Quantitative Structuralism: The Positivist Qualitative Research and the Paradigmatic Disclaimer. Qual. Quant. 2018, 52, 2063-2077. [CrossRef]

60. Creswell, J.; Plano, V. Designing and Conducting Mixed Methods Research; Sage Publications, Inc.: Thousand Oaks, CA, USA, 2007.

61. Kraus, S.; Ribeiro-Soriano, D.; Schüssler, M. Fuzzy-set Qualitative Comparative Analysis (fsQCA) in Entrepreneurship and Innovation Research-The Rise of a Method. Int. Entrep. Manag. J. 2018, 14, 15-33. [CrossRef]

62. Hair, J.; Anderson, R.; Tatham, R.; Black, W. Multivariate Data Analysis; Prentice-Hall: Upper Saddle River, PA, USA, 2005.

63. Armstrong, J.S.; Overton, T.S. Estimating Nonresponse Bias in Mail Surveys. J. Mark. Res. 1977, 14, $396-402$. [CrossRef]

64. Westland, J.C. Data Collection, Control, and Sample Size. In Structural Equation Models: From Paths to Networks; Westland, J.C., Ed.; Springer International Publishing: Cham, Switzerland, 2015; Volume 22, pp. 83-115.

65. Alegre, J.; Chiva, R. Assessing the Impact of Organizational Learning Capability on Product Innovation Performance: An Empirical Test. Technovation 2008, 28, 315-326. [CrossRef]

66. Chen, Y.H.; Lin, T.P.; Yen, D.C. How to facilitate Inter-Organizational Knowledge Sharing: The Impact of Trust. Inf. Manag. 2014, 51, 568-578. [CrossRef]

67. Molina-Azorín, J.F.; Claver-Cortes, E.; Pereira-Moliner, J.; Tarí, J.J. Environmental Practices and Firm Performance: An Empirical Analysis in the Spanish Hotel Industry. J. Clean. Prod. 2009, 17, 516-524. [CrossRef]

68. Podsakoff, P.M.; MacKenzie, S.B.; Lee, Y.; Podsakoff, N.P. Common Method Biases in Behavioral Research: A Critical Review of the Literature and Recommended Remedies. J. Appl. Psychol. 2003, 88, 879-903. [CrossRef] [PubMed]

69. Rennings, K.; Ziegler, A.; Ankele, K.; Hoffmann, E. The Influence of Different Characteristics of the EU Environmental Management and Auditing Scheme on Technical Environmental Innovations and Economic Performance. Ecol. Econ. 2006, 57, 45-59. [CrossRef]

70. Ziegler, A.; Nogareda, J.S. Environmental Management Systems and Technological Environmental Innovations: Exploring the Causal Relationship. Res. Policy 2009, 38, 885-893. [CrossRef]

71. Ragin, C.C. Redesigning Social Inquiry: Fuzzy Sets and Beyond; University of Chicago Press: Chicago, IL, USA, 2008.

72. Woodside, A.; Hsu, S.Y.; Marshall, R. General Theory of Cultures Consequences on International Tourism Behavior. J. Bus. Res. 2011, 64, 785-799. [CrossRef]

73. Woodside, A.G.; Prentice, C.; Larsen, A. Revisiting Problem Gamblers' Harsh Gaze on Casino Services: Applying Complexity Theory to Identify Exceptional Customers. Psychol. Mark. 2015, 32, 65-77. [CrossRef]

74. Fiss, P.C.; Sharapov, D.; Conqvist, L. Opposites Attract? Opportunities and Challenges for Integrating Large-N QCA and Econometric Analysis. Political Res. Q. 2013, 66, 191-235.

75. Ragin, C.C. Fuzzy-Set Social Science; Chicago University Press: Chicago, IL, USA, 2000.

76. Ragin, C.C. From Fuzzy Sets to Crisp Truth Tables; Working paper; University of Arizona: Tucson, AZ, USA, 2005.

77. Ragin, C.C. Qualitative Comparative Analysis using Fuzzy Sets (fsQCA). In Configurational Comparative Methods: Qualitative Comparative Analysis (QCA) and Related Techniques; Rihoux, B., Ragin, C.C., Eds.; Sage Publications: Thousand Oaks, CA, USA, 2009; pp. 87-121.

78. Woodside, A.; Zhang, M. Cultural Diversity and Marketing Transactions: Are Market Integration, Large Community Size, and World Religions Necessary for Fairness in Ephemeral Exchanges? Psychol. Mark. 2013, 30, 263-276. [CrossRef]

79. Molina-Azorín, J.F.; López-Gamero, M.D. Mixed Methods Studies in Environmental Management Research: Prevalence, Purposes and Designs. Bus. Strategy Environ. 2016, 25, 134-148. [CrossRef]

80. White, C.L.; Nielsen, A.E.; Valentini, C. CSR Research in the Apparel Industry: A Quantitative and Qualitative Review of Existing Literature. Corp. Soc. Responsib. Environ. Manag. 2017, 24, 382-394. [CrossRef] 
81. Song, W.; Yu, H. Green Innovation Strategy and Green Innovation: The Roles of Green Creativity and Green Organizational Identity. Corp. Soc. Responsib. Environ. Manag. 2018, 25, 135-150. [CrossRef]

82. Kraus, S.; Burtscher, J.; Niemand, T.; Roig-Tierno, N.; Syrjä, P. Configurational Paths to Social Performance in SMEs: The Interplay of Innovation, Sustainability, Resources and Achievement Motivation. Sustainability 2017, 9, 1828. [CrossRef]

83. Musa, M.H.; Mohamad, M.N. Importance of Green Innovation in Malaysian SMEs: Advantages and Future Research. Int. Acad. J. Bus. Manag. 2018, 5, 64-73.

(c) 2019 by the authors. Licensee MDPI, Basel, Switzerland. This article is an open access article distributed under the terms and conditions of the Creative Commons Attribution (CC BY) license (http:/ / creativecommons.org/licenses/by/4.0/). 